\title{
Understanding and Classification of Ocular Lymphomas
}

\author{
Valerie A. White \\ WHO/IARC Classification of Tumours Group, International Agency for Research on Cancer, Lyon, France
}

\section{Keywords}

Non-Hodgkin lymphoma - Ocular adnexal lymphoma .

Vitreoretinal lymphoma

\section{Abstract}

Background: Lymphomas that involve the tissues of the ocular adnexae and the eye itself can be confusing for both the new and seasoned learner alike. In this review, I present a simple way of classifying these disorders that will help to facilitate understanding of these myriad entities. Summary: Classifications of lymphomas have changed significantly over the last 40 years, but in recent decades, the basic structure of the WHO classification has remained the same, facilitating understanding. Key Messages: The ocular lymphomas can be divided into those that are external to the eye (ocular adnexae) and those that are internal (vitreoretinal and uveal). At each of these sites specific subtypes of lymphoma are common. Focusing on these common subtypes can aid the learner to create a scaffold that enables current understanding and upon which they can build for the future.

\section{KARGER}

(c) 2019 S. Karger AG, Basel

E-Mail karger@karger.com

www.karger.com/oop

\section{Lymphomas as my Entrance to Ophthalmic Pathology}

When, as a third year pathology resident in the 1980s, I was asked to review a series of orbital lymphoproliferative lesions, I did not know that I would be involved with these entities for the rest of my career. Some lesions were easy to classify as inflammatory, but others, such as those in Figure 1a were confusing: was this a lymphoma or a reactive lymphoid hyperplasia? From what I had learned about lymphomas up to that point in the pathological world, I thought it should have been called a low-grade lymphoma, and yet, the ophthalmic literature was still calling proliferations such as this one, lymphoid hyperplasia [1]. I published my first manuscript on ocular adnexal lymphoproliferative and inflammatory lesions without the benefit of immunohistochemistry or molecular pathology [2]. I only realized later that I was at the junction of a number of new technologies that would al-

Based on the 2nd Gordon Klintworth Lecture, Presented at the World Ophthalmology Congress, June 2018, Barcelona, Spain.

Valerie A. White MD, MHSc, FRCPC

WHO/IARC Classification of Tumours Group

International Agency for Research on Cancer

150 Cours Albert Thomas, FR-69372 Lyon Cedex 08 (France)

E-Mail whitev@iarc.fr 


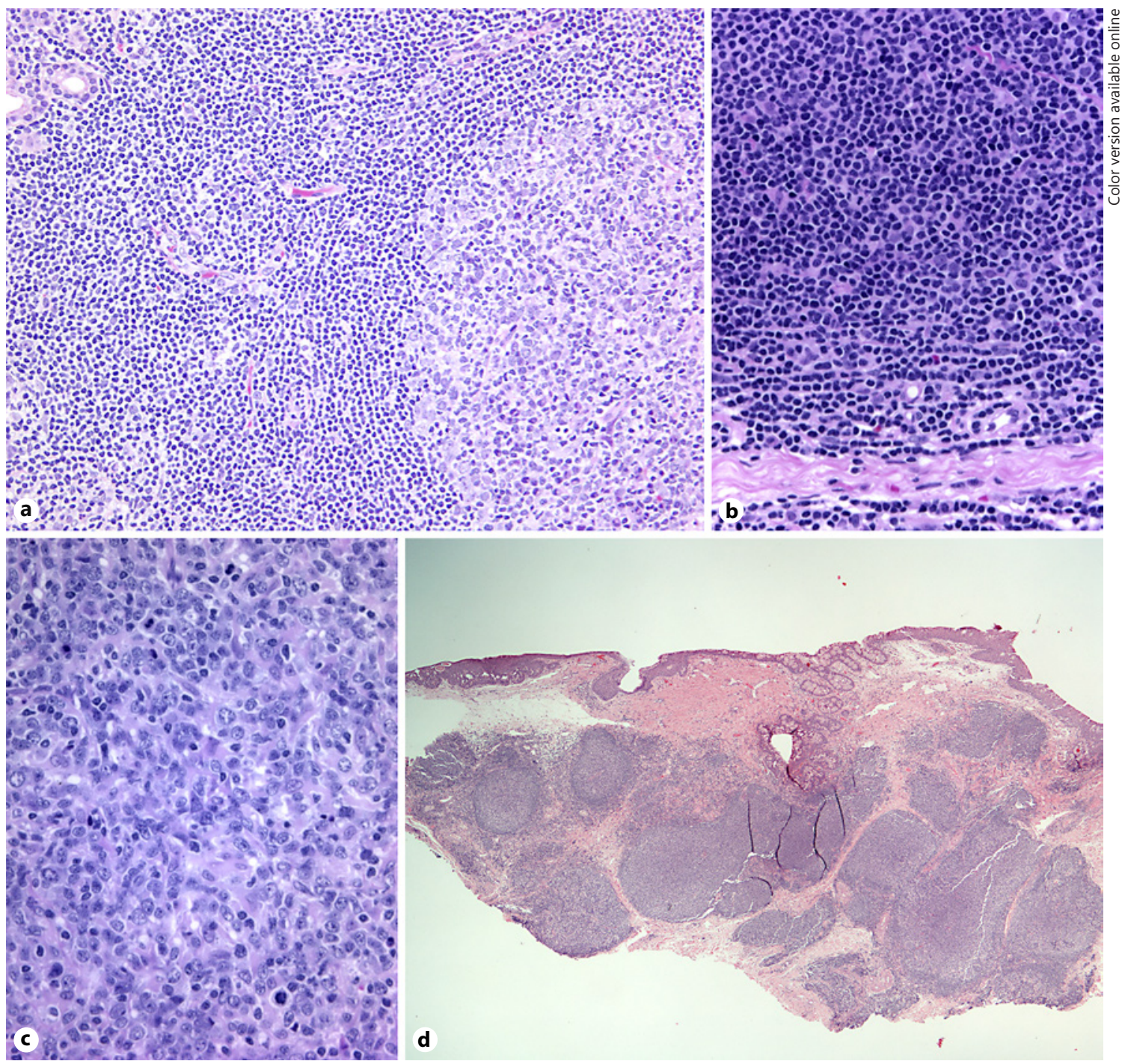

Fig. 1. a Photomicrograph showing a large germinal center at right surrounded by dense infiltrate of small, normal appearing lymphocytes. This appearance was mistaken as lymphoid hyperplasia for many years due to the reactive germinal center, now known to be common in EMZL (H\&E). b Dense infiltrate of small, almost normal appearing lymphocytes as seen in several types of small cell lymphomas, including EMZL, MCL, and SLL (H\&E). c Infiltrate of large, malignant lymphocytes with vesicular nuclei, prominent nucleoli and numerous mitotic figures, as seen in DLBCL (H\&E). d Low power photomicrograph of FL where recognition of the malignant follicles is essential. They are large, monotonous, and almost confluent with loss of the mantle zone (H\&E). low the delineation of MALT lymphoma: immunohistochemistry and the use of molecular genetics and cytogenetics in routine diagnostic pathology.

\section{Brief History of Lymphoma Classification}

When I came into pathology, my institution was using the Rappaport classification, initially published in 1956, and updated in 1966, for decision-making about treat- ment for lymphoma patients [3] I also learned the LukesCollins classification, first published in 1974, and understood the theoretical significance of T and B-cells, but this did not yet affect treatment. In North America, the Kiel classification did not gain a strong foothold, but the terms were used in publications therefore requiring some knowledge of it. My colleagues and I suffered through the Working Formulation, published in 1982 as it had replaced the Rappaport classification as the functional decision-making tool for treatment, dividing lymphomas 
into low, intermediate and high grade. In 1996, I published our first manuscript describing a series of ocular adnexal lymphoproliferative lesions, including the newly described entity of MALT lymphoma and utilizing molecular genetic investigations of IgH gene rearrangement [4]. We were relieved when the Revised European-American Lymphoma classification came along in 1994 as we hoped that finally there would be one classification and we would not have to learn a new one every few years. Explaining to our clinical colleagues what a lymphoma diagnosis in the new classification of the day meant in an older classification was becoming tedious and could possibly lead to errors in treatment. It also seemed reasonable that pathologists on both sides of the Atlantic, who were seeing similar types of tumors, should be diagnosing and classifying lymphomas in the same manner.

With cooperation enabled, the stage was set for the consensus meetings that led to the publication of the WHO Classification of Pathology and Genetics of Tumours of the Haematopoietic and Lymphoid Tissues in 2001 [5]. This classification brought together all the features known about a particular neoplasm: clinical, histological, immunohistochemical, molecular and cytogenetic, to shape its place in the classification. It also initiated attempts to relate a lymphoid neoplasm to its presumed normal counterpart within the development of a normal B- or T-lymphocyte. The classification was updated in 2008 as the 4th edition of the WHO Classification of Tumours of Haematopoietic and Lymphoid Tissues, a part of the WHO series on classification of neoplasms from all body sites [6].

\section{Current Classification}

The current classification is the revised 4th edition of the WHO Classification of Tumours of Haematopoietic and Lymphoid Tissues, published in 2017 [7]. The guiding principle in this classification remains the same: to use all information known about a particular hematopoietic neoplasm to place it in the classification. Entities are described under a routine series of headings (online suppl. Box 1; for all online suppl. material, see www.karger.com/ doi/10.1159/000499845), so that all information concerning a neoplasm is captured.

As in the previous edition, the lymphoid neoplasms are divided into 5 main categories:

(a) Precursor lymphoid neoplasms;

(b) Mature B-cell neoplasms;

(c) Mature T- and NK-cell neoplasms;

(d) Hodgkin lymphoma;

Lymphomas That Involve the Ocular Tissues (e) Immunodeficiency-associated lymphoproliferative disorders.

Histiocytic and dendritic cell neoplasms, although of a different lineage, often fall within the differential diagnosis of lymphoid neoplasms and I will consider this category briefly in this review.

\section{Epidemiology}

Non-Hodgkin lymphomas (NHL) are approximately the tenth most common cause of cancer worldwide [8]. Various reports have described the increasing incidence of NHL over the last few decades [9]. The same trend has been found for ocular adnexal sites [10-12]. As vitreoretinal lymphoma (VRL) is rarer it is more difficult to estimate its incidence and trends; however, this can be extrapolated by using data about primary central nervous system lymphoma, which has also shown an increase [13]. Previously we tried to estimate the incidence of VRL and also found it to be increasing [14]. Furthermore, lymphomas constitute the most common malignant orbital tumour in adults $[10,15]$.

\section{Lymphoma and the Eye}

Throughout my career, I have tried to simplify the learning process for both the student just beginning to learn about the complex topic of lymphomas and for the clinician trying to read around a specific entity to better understand and treat a particular patient.

There are several principles that can help the student (beginner or otherwise) of lymphomas that affect ophthalmic sites:

(a) Within the above classification, $>90 \%$ of lymphomas involving ophthalmic sites fall under the category of mature B-cell neoplasms. Hodgkin lymphoma almost never involves ophthalmic sites, while only small numbers of patients will have a lymphoma involving the eye or ocular adnexae that comes from one of the other 3 categories listed above. Therefore, in learning about lymphomas, the ophthalmologist should concentrate on learning about the mature B-cell neoplasms. And while there are about 40 types of mature B-cell neoplasms in the general classification, only a handful commonly affect ophthalmic sites (Table 1) [10,16,17]. A recent comprehensive review includes all lymphomas occurring in the ocular adnexa and the interested reader can consult this publication for information on the very rare subtypes,

Ocul Oncol Pathol 2019;5:379-386 381 
Table 1. Immunophenotype of common ocular adnexal lymphomas

\begin{tabular}{llllll}
\hline Lymphoma type* $^{*}$ & CD5 & CD10 & BCL2 & BCL6 & Cyclin D1 \\
\hline EMZL & - & - & + (diffuse) & - & - \\
FL & - & + & + (within follicles) & + & - \\
MCL & + & - & + (diffuse $)$ & - & + \\
SLL/CLL & + & - & - & $-/+$ & - \\
DLBCL & - & $-/+$ & $-/+$ & - \\
\hline
\end{tabular}

* All of these lymphomas are positive with B-cell markers CD20, CD79a, and PAX5.

EMZL, extranodal marginal zone lymphoma; FL, follicular lymphoma; MCL, mantle cell lymphoma; SLL/ CLL, small lymphocytic lymphoma/chronic lymphocytic leukemia; DLBCL, diffuse large B-cell lymphoma.

such as plasmacytoma, Burkitt lymphoma, lymphoplasmacytic lymphoma, and others [17].

(b) Morphologically lymphomas can be divided into those composed of "small," almost normal appearing lymphocytes (Fig. 1b), and those that are composed mainly of "large," malignant appearing lymphoid tumour cells (Fig. 1c). This distinction is critical to the pathologist making a lymphoma diagnosis.

(c) Lymphomas that involve the ocular adnexae (orbit, conjunctiva, lacrimal gland, eyelid) are distinctly different from those involving the retina and vitreous cavity [18].

(d) In general, those that involve the ocular adnexae are composed of various types of small B-lymphocytes (Fig. 1b) and generally have a good prognosis, while VRLs are composed of large malignant B-cells (Fig. 1c) and have a poor prognosis, as there is often associated brain involvement.

\section{Updates in Current Classification Pertaining to Specific Ocular Lymphoid and Histiocytic Neoplasms}

\section{Extranodal Marginal Zone Lymphoma of \\ Mucosa-Associated Lymphoid Tissue}

Extranodal marginal zone lymphoma of mucosa-associated lymphoid tissue (EMZL) is the most common lymphoma involving the ocular adnexae, accounting for $50-70 \%$ of cases depending on the series. It is the most common type of lymphoma involving extranodal sites throughout the body. It can be morphologically recognized by its heterogeneous appearance and variable presence of germinal centres, small lymphocytes, monocytoid lymphocytes, and plasma cells. Lymphoepithelial lesions may also be present if the lymphoma involves the conjunctiva or lacrimal apparatus. EMZL is an im- munophenotypic diagnosis of exclusion as it has no specific positively staining marker and a secure diagnosis relies on the exclusion of the other types of small cell lymphomas that occur in the ocular adnexae. Fortunately, this can be accomplished with a relatively small panel of immunohistochemical stains (Table 1). For example, follicular lymphoma (FL) is ruled out by the lack of a regular follicular architecture with numerous monotonous appearing follicles that contain lymphocytes with irregular nuclei that stain positively for BCL-2 in most cases (Fig. 1d and section on FL). Along with appropriate histology, chronic lymphocytic leukemia/ small lymphocytic lymphoma (CLL/SLL) is ruled out by positive staining for CD5 and a lack of cyclin D1 staining, and mantle cell lymphoma (MCL) is ruled out by a lack of follicles and positive staining for CD5 and cyclin D1.

Often, because of its heterogeneous appearance, the differential diagnosis for EMZL is not between another lymphoma, but with a reactive disorder, particularly in the conjunctiva where reactive lymphoid proliferations are common. In this situation, molecular genetic investigation for immunoglobulin gene rearrangement should be performed to determine if a monoclonal population of B-cells is present. This investigation, usually done by PCR, should be performed in virtually all cases of lymphoproliferative disorders composed of populations of small lymphocytes, and especially with small, crushed or suboptimal biopsies. The presence of a monoclonal population of B-cells in a lesion with appropriate histology confirms the diagnosis of a B-cell lymphoma. PCR can also be used to diagnose a T-cell clonal disorder if this is in the differential diagnosis and can confirm the presence of the $t(14 ; 18)$ translocation in FL. With the use of better primers, there are few false negatives with this test. 
Unlike EMZL involving the GI tract and its association with Helicobacter pylori infection, no definite association has been demonstrated in OAL despite numerous studies, mostly focusing on Chlamydia psittaci. In some locations of the world, there is a high prevalence of the organism in patients with OAL, but not in others [19]. Studies of the patterns of somatic gene mutations of the immunoglobulin genes in EMZL show limited diversity, suggesting the role of chronic infection, autoimmune disease or antigen stimulation in the pathogenesis, but this has not been proved yet [20]. Thus, the normal counterpart of EMZL is thought to be a post-germinal center memory $\mathrm{B}$-cell. Despite the indolence of EMZL, it has complex genetics, which are beyond the scope of this article, involving translocations, trisomies, and other mutations, all having the effect of activation of the NF-kB pathway [21].

\section{Follicular Lymphoma}

Depending on the study, FL is the second or third most common OAL $[16,17]$. In about a third of cases, the patient has concurrent or prior systemic lymphoma. As the name implies, FL usually shows numerous neoplastic follicles with a monotonous appearance composed of small lymphoma cells with irregular, twisted nuclei (called centrocytes) admixed with large lymphoma cells that have vesicular nuclei and prominent nucleoli (centroblasts; Fig. 1d). The mantle zones of the follicles are effaced and the follicles lack the tingible-body macrophages seen in normal reactive follicles. These neoplastic follicles stain for BCL-2, indicating the presence of the 14;18 translocation, which is the hallmark of FL; benign follicles are negative for this stain. FL is one of the few lymphomas that require grading, which depends upon the number of centroblasts within the neoplastic follicles. In a recent multicenter review of ocular adnexal FL, $80 \%$ were low-grade 1-2 and these patients had fewer relapses than those with grade 3 FL $[22,23]$. A small percentage of FL s may transform into diffuse large B-cell lymphoma (DLBCL), heralding the poorer prognosis of that lymphoma type.

\section{Mantle Cell Lymphoma}

Of the 4 main types of small B-cell OAL, MCL is distinctive by having a poor prognosis. Normally a nodal lymphoma, when extranodal, it does have a propensity to involve the ocular adnexae in older males, frequently with bilateral involvement of upper and lower orbits and stage IV disease, as first demonstrated in our publication on this entity [24, 25]. Peripheral blood involvement occurs in almost all patients, some of whom may have a marked lymphocytosis. Histologically MCL has a rather monoto-

Lymphomas That Involve the Ocular Tissues nous appearance with a distinctive immunophenotype of CD5 and nuclear cyclin D1 positivity, and a high mitotic index in the majority of cases. It is characterized by a $t(11$; 14) translocation that upregulates CCND1 (BCL1), the gene encoding cyclin D1. The postulated normal counterpart of most MCL is a pre-germinal center B-cell of the inner mantle zone.

Recently, more indolent forms of MCL have been recognized in a leukemic non-nodal form and in-situ MCL, but these have not yet been described in ophthalmic patients.

Patients with MCL must be treated aggressively if they can tolerate it. Survival has improved with the addition of rituximab to CHOP therapy, but median survival is still poor at 3-5 years. High mitotic rate and/or proliferation index are associated with poor prognosis and should be evaluated in each case [3].

\section{Chronic Lymphocytic Leukemia/Small Lymphocytic Lymphoma}

CLL is the most common leukemia of adults. CLL is diagnosed when there are $>5 \times 10^{9} / \mathrm{L}$ monoclonal B-cells with characteristic morphology and phenotype in the peripheral blood. SLL is the solid counterpart involving nodes or extranodal sites usually with a peripheral blood count of $<5 \times 10^{9} / \mathrm{L}$. Despite this, it is relatively rare in ophthalmic sites responsible for approximately $5 \%$ of cases. SLL is usually CD5 positive but negative for cyclin D1, distinguishing it from MCL. The cells are small, only slightly irregular lymphocytes and the histologic appearance is monotonous apart from occasional pale areas of larger cells, the proliferation centers containing a continuum of small lymphocytes, prolymphocytes, and paraimmunoblasts, which may be confused with germinal centres. Of interest is that there is an inherited component to SLL/CLL with a familial predisposition of 5-10\% in first-degree relatives. It has also been determined that most cases of CLL/SLL are preceded by a monoclonal Bcell lymphocytosis of $<5 \times 10^{9} / \mathrm{L}$. The postulated normal counterpart is an antigen-experienced mature CD5+ Bcell with mutated or unmutated immunoglobulin heavy chain variable genes. The molecular genetic landscape of CLL/SLL is complex with no specific genetic marker that identifies the majority of cases. Less than $10 \%$ of CLL/SLL may also transform into DLBCL.

\section{Diffuse Large B-Cell Lymphoma}

DLBCL is the most common lymphoma when considering all body sites, responsible for approximately $40 \%$ of cases, yet it is responsible for $<10 \%$ of ocular adnexal cas- 
es $[16,26]$. As the name implies, the histological appearance is of sheets of large malignant appearing lymphocytes with vesicular nuclei, prominent nucleoli, and numerous mitotic figures (Fig. 1c). The appearance is obviously malignant and the differential diagnosis may include carcinoma or melanoma. There are numerous subtypes of DLBCL that often arise in specific body sites, but those that involve the ocular adnexae fall into the "NOS or not otherwise specified" category. DLBCL were initially subdivided by gene expression profiling into 2 groups: the germinal center subtype and activated $\mathrm{B}$-cell subtype (ABC). This distinction can now be performed in many cases by immunohistochemistry, where CD10 and BCL6 positivity define the germinal center subtype and IRF4/MUM1 positivity defines the ABC subtype, although some cases remain unclassifiable. These distinctions are important, as the subtype may dictate treatment and determine prognosis.

In a recent study of 100 patients with DLBCL involving the ocular adnexae, Munch-Petersen et al. [27] found that 57 were primary, 29 were associated with concurrent systemic lymphoma, and 14 were a relapse of previous systemic lymphoma. Even though a thorough history and staging of all OAL patients should be carried out, this study indicates that patients with DLBCL are much more likely than those with small cell types of OAL to have either prior or concurrent evidence of systemic lymphoma $[27,28]$. In their retrospective study, the median overall survival was only 3.5 years.

\section{Vitreoretinal Lymphoma}

Even though it is a subtype of DLBCL, VRL differs from other subtypes of DLBCL, and is a distinctly different disease from OAL. Within the WHO classification it is included within the category of primary DLBCL of the CNS, with which vitreoretinal disease is often associated. This type of lymphoma may begin in the brain or vitreous/retina and then spread to the other site and/or the testis, all immune-privileged sites. Most cases are of the $\mathrm{ABC}$ subtype, which is partially responsible for the poor progression-free survival of 11 months and median overall survival of 33 months [14].

VRL is the masquerade of vitritis and vitreoretinitis, so nearly all cases must be diagnosed by cytological examination of vitreous fluid obtained at diagnostic or therapeutic vitrectomy (often called vitreous biopsy, although it is not a tissue biopsy). These specimens are fragile and should be handled immediately by the laboratory to obtain accurate diagnostic results. Classically these lymphomas have been difficult to diagnose due to the paucity of diagnostic malignant lymphoma cells, which are usually admixed with pyknotic tumor cells and inflammatory cells that may obscure the malignant cells. Sometimes sufficient material is obtained to perform immunoglobulin gene rearrangement studies and immunophenotyping $[29,30]$. The cells are large with vesicular nuclei and prominent nucleoli and must be distinguished from reactive macrophages that are often present in vitreous samples.

Recently, mutations of the MYD88 gene on chromosome 3 p22, a myeloid differentiation gene, have been identified in most cases of VRL and primary central nervous system lymphoma [31,32]. This mutation has been identified in other types of lymphoma, and so is not specific for lymphoma type; however, within the vitreous fluid, recognition of this mutation may be the definitive test that can provide a confident diagnosis when cellular material is equivocal.

It should be noted that there are very rare intraocular lymphomas, mostly of the EMZL type that involve the uveal tract, which should not be confused with VRL [18].

\section{Histiocytic Diseases}

Langerhans cell histiocytosis/Erdheim-Chester Disease (LCH/ECD). As the number and complexity of the lymphoid neoplasms has burgeoned, so too have those of the histiocytic/dendritic cell group. In 2016, Emile et al. [33] published a new classification of these disorders based on consensus meetings of the Histiocyte society, which, as with lymphoid neoplasms, took into consideration all known features of these heterogeneous diseases, including clinical, radiologic, pathological, phenotypic, genetic, and/or molecular characteristics (online suppl. Box 2). This classification is somewhat different from the WHO classification, as it also encompasses nonmalignant as well as malignant disorders. Although rare, both benign and malignant histiocytic disorders may involve the ocular tissues.

The significant change is that LCH and ECD are both now classified as malignancies due to the recent finding of somatic mutations in the MAPK pathway, most importantly, those of BRAF V600 $[34,35]$. This differs from when I participated in a review of orbital xanthogranulomatous disorders that helped to classify and clarify the features of this unusual group of lesions and how they affected the ocular adnexae, as at that time they were still considered inflammatory diseases [36].

While the immunophenotype of LCH and ECD is different, these 2 disorders have overlapping histologies and sites of involvement. Both are composed of mix- 
Table 2. Immunophenotype of some histiocytic disorders that involve the ocular adnexae

\begin{tabular}{lllllll}
\hline Disorder & CD68/CD163 & S100 & CD1a & Langerin CD207 & Birbeck granules & Multifocal disease \\
\hline LCH & + & + & + & + & + & $+/-$ \\
ECD & + & - & - & - & - & + \\
JXG & + & - & - & - & - & $+/-$ \\
RDD & + & + & - & - & - & $+/-$
\end{tabular}

LCH, Langerhan cell histiocytosis; ECD, Erdheim-Chester disease; JXG, Juvenile xanthogranuloma; RDD, Rosai-Dorfman disease.

tures of histiocytes, the defining cell, and other inflammatory cells. LCH cells are defined by the S100, Cd1a, langerin positive immunophenotype and contain Birbeck granules, which can be shown only by electron microscopy. The histiocytic cells in ECD are negative for the above immunomarkers and do not contain Birbeck granules (Table 2). While ECD is usually multifocal, LCH can be multifocal in children, where it may be a severe and fatal disease, or a relatively benign unifocal lesion in children or adults. This perplexed researchers for many years and was one of the reasons that this disorder was not considered a malignancy until recently. Recent work has shown that the complexity of LCH may be due to the stage of myeloid differentiation at which the somatic mutations are acquired [37]. The inflammatory cells that comprise most of the bulk of these lesions are due to the secretion of chemokines.

The differential diagnosis of these 2 malignant disorders is comprised of 2 other usually benign histiocytic disorders, juvenile xanthogranuloma and Rosai-Dorfman disease that also can affect ophthalmic sites. In addition it has now been recognized that 1 patient may even have combinations of these disorders. The understanding and mystery involved in the relationship between clinical, morphologic and genetic information of these complex disorders is just beginning to be unraveled and is sure to evolve in the next several years.

\section{Staging of Ocular Adnexal Lymphomas}

Since the 7th edition of the AJCC TNM classification, OAL have been included in the staging system for ophthalmic neoplasms. Currently the 8th edition contains an updated TNM classification [38]. OAL were included in the TNM system as the Lugano system (and formerly the Ann Arbor system) used for staging all NHL, was not detailed enough to show differences in outcome, as the vast majority of OAL were staged as 1E. The current TNM system takes into account the specific location of the lymphoma around the eye. There have been a few studies since the publication of this system that show differences in disease specific survival that are dependent on the stage of disease $[38,39]$.

\section{Summary}

Lymphomas are common neoplasms that vary greatly on how they will affect the lives of patients and their visual health. By concentrating on a handful of lymphoma subtypes, the ophthalmologist can focus on understanding the diseases that matter to them and their patients.

\section{Statement of Ethics}

The author has no ethical conflicts to disclose.

\section{Disclosure Statement}

The author declares no disclosures or conflicts of interest.

\section{Funding Sources}

This study did not receive any funding.

\section{Author Contributions}

The author is a staff member of the International Agency for Research on Cancer/World Health Organization. The author alone is responsible for the views expressed in this article and they do not necessarily represent the decisions, policy or views of the International Agency for Research on Cancer/World Health Organization. 


\section{References}

1 Knowles DM, Jakobiec FA, McNally L, Burke JS. Lymphoid hyperplasia and malignant lymphoma occurring in the ocular adnexa (orbit, conjunctiva, and eyelids): a prospective multiparametric analysis of 108 cases during 1977 to 1987. Hum Pathol. 1990 Sep;21(9):959-73.

2 White V, Rootman J, Quenville N, Worth A, Robertson W. Orbital lymphoproliferative and inflammatory lesions. Can J Ophthalmol. 1987 Dec;22(7):362-73.

3 Swerdlow SH. Lymphoma classification and the tools of our trade: an introduction to the 2012 USCAP Long Course. Mod Pathol. 2013 Jan;26(Suppl 1):S1-14.

4 White VA, Gascoyne RD, McNeil BK, Chang WY, Brewer LV, Rootman J. Histopathologic findings and frequency of clonality detected by the polymerase chain reaction in ocular adnexal lymphoproliferative lesions. Mod Pathol. 1996 Nov;9(11):1052-61.

5 Jaffe ES, Stein H, Vardiman JW, editor. Pathology and Genetics of Tumours of the Haematopoeitic and Lymphoid Tissues. 3rd edition. Lyon: IARC Press; 2001.

6 Swerdlow SH, Harris NL, Jaffe ES, Pileri SA, Stein H, Thiele J. Vardiman JW, editor. WHO Classification of Tumours of Haematopoietic and Lymphoid Tissues. 4th edition. Lyon: IARC; 2008.

7 Swerdlow SH, Harris NL, Jaffe ES, Pileri SA, Stein H, Thiele J, editors. WHO Classification of Tumours of Haematopoietic and Lymphoid Tissues. 4th Revised Edition. Lyon: IARC; 2017.

8 Ferlay JL, Colombet M, Mery L, Pineros M, Znaor A, Soerjomataram I, et al. Global Cancer Observatory: Cancer Today. Lyon: IARC; 2018.

9 Smith A, Crouch S, Lax S, Li J, Painter D, Howell D, et al. Lymphoma incidence, survival and prevalence 2004-2014: sub-type analyses from the UK's Haematological Malignancy Research Network. Br J Cancer. 2015 Apr;112(9):1575-84.

10 Hassan WM, Bakry MS, Hassan HM, Alfaar AS. Incidence of orbital, conjunctival and lacrimal gland malignant tumors in USA from Surveillance, Epidemiology and End Results, 1973-2009. Int J Ophthalmol. 2016 Dec;9(12): 1808-13.

11 Moslehi R, Coles FB, Schymura MJ. Descriptive epidemiology of ophthalmic and ocular adnexal non-Hodgkin's lymphoma. Expert Rev Ophthalmol. 2011;6(2):175-80.

12 Moslehi R, Schymura MJ, Nayak S, Coles FB. Ocular adnexal non-Hodgkin's lymphoma: a review of epidemiology and risk factors. Expert Rev Ophthalmol. 2011 Apr;6(2):181-93.

13 Shiels MS, Pfeiffer RM, Besson C, Clarke CA, Morton LM, Nogueira L, et al. Trends in primary central nervous system lymphoma incidence and survival in the U.S. Br J Haematol. 2016 Aug;174(3):417-24.
14 Levasseur SD, Wittenberg LA, White VA. Vitreoretinal lymphoma: a 20-year review of incidence, clinical and cytologic features, treatment, and outcomes. JAMA Ophthalmol. 2013 Jan;131(1):50-5.

15 Kim UR, Khazaei H, Stewart WB, Shah AD. Spectrum of orbital disease in South India: an aravind study of 6328 consecutive patients. Ophthal Plast Reconstr Surg. 2010 Sep-Oct; 26(5):315-22.

16 Ferry JA, Fung CY, Zukerberg L, Lucarelli MJ, Hasserjian RP, Preffer FI, et al. Lymphoma of the ocular adnexa: A study of 353 cases. Am J Surg Pathol. 2007 Feb;31(2):170-84.

17 Olsen TG, Heegaard S. Orbital lymphoma. Surv Ophthalmol. 2019 Jan-Feb;64(1):45-66.

18 Coupland SE, Damato B. Understanding intraocular lymphomas. Clin Exp Ophthalmol. 2008 Aug;36(6):564-78.

19 Husain A, Roberts D, Pro B, McLaughlin P, Esmaeli B. Meta-analyses of the association between Chlamydia psittaci and ocular adnexal lymphoma and the response of ocular adnexal lymphoma to antibiotics. Cancer. 2007 Aug;110(4):809-15.

20 Wotherspoon AC. Extranodal and splenic small B-cell lymphoma. Mod Pathol. 2013 Jan;26(Suppl 1):S29-41.

21 Schreuder MI, van den Brand M, Hebeda KM, Groenen PJ, van Krieken JH, Scheijen B. Novel developments in the pathogenesis and diagnosis of extranodal marginal zone lymphoma. J Hematop. 2017 Sep;10(3-4):91-107.

22 Rasmussen PK, Ralfkiaer E, Prause JU, Sjö LD, Specht L, Rossing HH, et al. Follicular lymphoma of the ocular adnexal region: a nation-based study. Acta Ophthalmol. 2015 Mar;93(2):184-91.

23 Rasmussen PK, Coupland SE, Finger PT, Graue GF, Grossniklaus HE, Honavar SG, et al. Ocular adnexal follicular lymphoma: a multicenter international study. JAMA Ophthalmol. 2014 Jul;132(7):851-8.

24 Looi A, Gascoyne RD, Chhanabhai M, Connors JM, Rootman J, White VA. Mantle cell lymphoma in the ocular adnexal region. Ophthalmology. 2005 Jan;112(1):114-9.

25 Knudsen MK, Rasmussen PK, Coupland SE, Esmaeli B, Finger PT, Graue GF, et al. Clinicopathological Features of Ocular Adnexal Mantle-Cell Lymphoma in an International Multicenter Cohort. JAMA Ophthalmol. 2017 Dec;135(12):1367-74.

26 Olsen TG, Holm F, Mikkelsen LH, Rasmussen PK, Coupland SE, Esmaeli B, et al. Orbital Lymphoma-An International Multicenter Retrospective Study. Am J Ophthalmol. 2019 Mar;199:44-57.

27 Munch-Petersen HD, Rasmussen PK, Coupland SE, Esmaeli B, Finger PT, Graue GF, et al. Ocular adnexal diffuse large B-cell lymphoma: a multicenter international study. JAMA Ophthalmol. 2015 Feb;133(2):165-73.
28 Peleg A, Heran MK, White VA, Chang WY, Rootman J. Malignant lymphoproliferative disorders extending into the orbit from the paranasal sinuses. Orbit. 2009;28(2-3): 80-7.

29 Wittenberg LA, Maberley DA, Ma PE, Wade NK, Gill H, White VA. Contribution of vitreous cytology to final clinical diagnosis fifteenyear review of vitreous cytology specimens from one institution. Ophthalmology. 2008 Nov;115(11): 1944-50.

30 White VA, Gascoyne RD, Paton KE. Use of the polymerase chain reaction to detect Band T-cell gene rearrangements in vitreous specimens from patients with intraocular lymphoma. Arch Ophthalmol. 1999 Jun; 117(6):761-5.

31 Bonzheim I, Giese S, Deuter C, Süsskind D, Zierhut M, Waizel M, et al. High frequency of MYD88 mutations in vitreoretinal B-cell lymphoma: a valuable tool to improve diagnostic yield of vitreous aspirates. Blood. $2015 \mathrm{Jul}$ 126(1):76-9.

32 Araujo I, Coupland SE. Primary Vitreoretinal Lymphoma- A Review. Asia Pac J Ophthalmol (Phila). 2017 May-Jun;6(3):283-9.

33 Emile JF, Abla O, Fraitag S, Horne A, Haroche J, Donadieu J, et al.; Histiocyte Society. Revised classification of histiocytoses and neoplasms of the macrophage-dendritic cell lineages. Blood. 2016 Jun;127(22):2672-81.

34 Emile JF, Diamond EL, Hélias-Rodzewicz Z Cohen-Aubart F, Charlotte F, Hyman DM, et al. Recurrent RAS and PIK3CA mutations in Erdheim-Chester disease. Blood. 2014 Nov; 124(19):3016-9.

35 Go H, Jeon YK, Huh J, Choi SJ, Choi YD, Cha $\mathrm{HJ}$, et al. Frequent detection of BRAF(V600E) mutations in histiocytic and dendritic cell neoplasms. Histopathology. 2014 Aug;65(2): 261-72.

36 Sivak-Callcott JA, Rootman J, Rasmussen SL, Nugent RA, White VA, Paridaens D, et al. Adult xanthogranulomatous disease of the orbit and ocular adnexa: new immunohistochemical findings and clinical review. Br J Ophthalmol. 2006 May;90(5):602-8.

37 Allen CE, Merad M, McClain KL. Langerhans-Cell Histiocytosis. N Engl J Med. 2018 Aug;379(9):856-68.

38 Sniegowski MC, Roberts D, Bakhoum M, Mc Laughlin P, Yin VT, Turturro F, et al. Ocular adnexal lymphoma: validation of American Joint Committee on Cancer seventh edition staging guidelines. Br J Ophthalmol. 2014 Sep;98(9):1255-60.

39 Rath S, Connors JM, Dolman PJ, Rootman J, Rootman DB, White VA. Comparison of American Joint Committee on Cancer TNMbased staging system (7th edition) and Ann Arbor classification for predicting outcome in ocular adnexal lymphoma. Orbit. 2014 Feb; 33(1):23-8 